\title{
Gravimetric geoid modeling from the combination of satellite gravity model, terrestrial and airborne gravity data: a case study in the mountainous area, Colorado
}

\author{
Tao Jiang ${ }^{*}$ (D) Yamin Dang and Chuanyin Zhang
}

\begin{abstract}
Constructing a high-precision and high-resolution gravimetric geoid model in the mountainous area is a quite challenging task because of the lack of terrestrial gravity observations, rough topography and the geological complexity. One way out is to use high-quality and well-distributed satellite and airborne gravity data to fill the gravity data gaps; thus, the proper combination of heterogeneous gravity datasets is critical. In a rough topographic area in Colorado, we computed a set of gravimetric geoid models based on different combination modes of satellite gravity models, terrestrial and airborne gravity data using the spectral combination method. The gravimetric geoid model obtained from the combination of satellite gravity model GOCO06S and terrestrial gravity data agrees with the GPS leveling measured geoid heights at 194 benchmarks in $5.8 \mathrm{~cm}$ in terms of the standard deviation of discrepancies, and the standard deviation reduces to $5.3 \mathrm{~cm}$ after including the GRAV-D airborne gravity data collected at $\sim 6.2 \mathrm{~km}$ altitude into the data combination. The contributions of airborne gravity data to the signal and accuracy improvements of the geoid models were quantified for different spatial distribution and density of terrestrial gravity data. The results demonstrate that, although the airborne gravity survey was flown at a high altitude, the additions of airborne gravity data improved the accuracies of geoid models by $13.4 \%-19.8 \%$ in the mountainous area (elevations $>2000 \mathrm{~m}$ ) and $12.7 \%-21 \%$ (elevations $<2000 \mathrm{~m}$ ) in the moderate area in the cases of terrestrial gravity data spacings are larger than $15 \mathrm{~km}$.
\end{abstract}

Keywords: Airborne gravity, Colorado experiment, Geoid, Geoid-quasigeoid separation, Spectral combination, Spectral weight, Terrestrial gravity

\section{Introduction}

In 2017, The Joint Working Group (JWG) 0.1.2 (Strategy for the Realization of the International Height Reference System (IHRS)) and JWG 2.2.2 (the $1 \mathrm{~cm}$ geoid experiment) of the International Association of Geodesy (IAG) jointly launched the Colorado geoid experiment. The goal of this experiment is to assess the repeatability of gravity potential values as IHRS coordinates using different geoid

\footnotetext{
${ }^{*}$ Correspondence: jiangtao@casm.ac.cn

Chinese Academy of Surveying and Mapping, 28 Lianhuachi West Rd, Haidian, Beijing 100036, China
}

modeling methods, and to compare and evaluate the corresponding gravimetric geoid models. In this frame, the National Geodetic Survey (NGS) of the United States of America (USA) provided the geodesy community with terrestrial, airborne gravity and GPS (global positioning system) leveling data as well as digital elevation model (DEM) for a mountainous area of about 400 thousand $\mathrm{km}^{2}$ in Colorado, which allowed the comparison of different methods and softwares for geoid computation using the same input dataset in this challenging area.

The experiment area is covered by both terrestrial and airborne gravity data, which are not only different 
in spatial distribution and spectral contents, but also in their error characteristics. Nowadays, satellite gravity models are routinely used to provide accurate long wavelength gravity field information for regional geoid modeling, while terrestrial and airborne gravity data contribute the medium and short wavelengths of gravity field. The major challenge for geoid modeling in this area is the proper combination of satellite gravity model, terrestrial and airborne gravity data.

The commonly used approaches for the combination of Earth gravity model, terrestrial and airborne gravity data can be divided into three categories. In the first approach, the airborne gravity data are firstly downward continued from the flight altitude to the ground or geoid to merge with the terrestrial gravity data, then the merged gravity data are used to compute the geoid by Stokes' integral (Novak and Heck 2002; Bayoud and Sideris 2003; Hwang et al. 2007; Forsberg et al. 2000, 2012; Jekeli et al. 2013) or least squares collocation (Hwang et al. 2007; Scheinert et al. 2008; Shih et al. 2015). However, this approach involves two-step processing of airborne gravity data, introducing the edge effects twice. Additionally, the combination of different datasets is not weighted according to their spectral contents. The second approach is the least squares collocation (LSC) which combines all the input data and compute the geoid in one step (Hwang et al. 2007; Forsberg and Olesen 2010). The main advantage of LSC is that it can accommodate inhomogeneous data of different types and spatial resolutions. However, for application on massive datasets in large areas, the computation efforts involved are excessive to afford. The third approach is the spectral combination proposed by Wenzel (1982) and Sjöberg (1981), which can lead to a geoid solution with minimum least squares error if the spectral weights of each dataset are determined properly. The combination of terrestrial and airborne gravity data can be done in one step by means of spectral weights in surface integrals. It allows the integration of a great amount of gravity data in an efficient way on the contrary to LSC, and provides a flexible control on the data combination by spectral weights (Jiang and Wang 2016). In addition to these three approaches, radial base functions and wavelets can also be used for the combination of different types of gravity data, interested readers are referred to (Schmidt et al 2007; Klees et al 2008; Wittwer 2009; Panet et al 2010).

As a result, we used the spectral combination method for geoid determination in Colorado as our contribution to the geoid experiment. This paper summarizes the method, procedure, data, results and analyses of our Colorado geoid modeling experiment. Several gravimetric geoid models in Colorado were computed from different combination modes of satellite gravity models, terrestrial and airborne gravity data. The derived geoid models were then validated and compared using the high-precision GPS leveling measured geoid heights. Moreover, the contributions of airborne gravity data to geoid modeling were quantitatively evaluated for different data combination modes and terrestrial gravity data conditions.

Gravimetric geoid modeling method is presented in Sect. 2. Section 3 describes the Colorado geoid experiment and the data used in this experiment. The geoid computations, results and analyses are explicated in detail in Sects. 4 and 5. Conclusions are given in Sect. 6.

\section{Gravimetric geoid modeling method}

The spectral combination of satellite gravity model, terrestrial and airborne gravity data is performed in Molodensky's theoretic frame. Molodensky's harmonic continuation method is employed to solve the geodetic boundary value problem (Heiskanen and Moritz 1967, p. 312; Hofmann-Wellenhof and Moritz 2005, p. 303-308; Wang et al. 2012); thus, the quasigeoid heights (height anomalies) are firstly computed and then need to be transformed into the geoid heights. Remove-compute-restore procedure with a high-degree Earth gravity model, e.g., the Earth Gravitational Model of 2008 (EGM08, Pavlis et al 2012, 2013), is applied to account for the contribution outside local gravity data coverage. Residual terrain model (RTM) is used to represent the short wavelength components of gravity field generated by the high-frequency part of topography (Frosberg 1984).

For the spectral combination of satellite gravity model, terrestrial and airborne gravity data, the gravimetric geoid height can be decomposed into three components contributed from each dataset:

$$
N=\zeta_{\text {Sat }}+\zeta_{\text {Ter }}+\zeta_{\text {Air }}+\zeta_{0}+\Delta,
$$

where $N$ is the gravimetric geoid height, $\zeta_{\text {Sat }}, \zeta_{\text {Ter }}$ and $\zeta_{\text {Air }}$ are the height anomaly contribution of the satellite gravity model, terrestrial and airborne gravity data, respectively, $\zeta_{0}$ is the zero-degree term of height anomaly, and $\Delta$ is the geoid-quasigeoid separation term.

Applying the classical remove-compute-restore procedure with a high-degree reference gravity model and representing the frequency gravity effects by the residual terrain model (Forsberg 1984), $\zeta_{\text {Ter }}$ and $\zeta_{\text {Air }}$ can be further decomposed and Eq. (1) is written as

$$
N=\zeta_{\text {Sat }}+\left(\zeta_{\text {Ter }}^{\text {Res }}+\zeta_{\text {Ter }}^{R e f}\right)+\left(\zeta_{\text {Air }}^{\text {Res }}+\zeta_{\text {Air }}^{\text {Ref }}\right)+\zeta^{R T M}+\zeta_{0}+\Delta
$$

where $\zeta_{\mathrm{Ter}}^{\mathrm{Res}}$ is the residual height anomaly derived from terrestrial gravity data, and $\zeta_{\mathrm{Ter}}^{\mathrm{Ref}}$ is the reference height anomaly corresponding to terrestrial gravity. $\zeta_{\text {Air }}^{\text {Res }}$ and 
$\zeta_{\text {Air }}^{\text {Ref }}$ are the corresponding terms of airborne gravity data, respectively. $\zeta^{R T M}$ is the RTM effect of height anomaly, restoring the topographic effects which have been removed when computing the residual terrestrial gravity anomaly and the residual airborne gravity disturbance.

$\zeta_{\text {Sat }}$ can be computed from potential coefficients of the satellite gravity model using spectral weights $W_{\text {Sat }}(n)$. $\zeta_{\mathrm{Ter}}^{\text {Res }}$ is computed from residual terrestrial gravity anomalies using the Stokes' integral with spectral weights $W_{\text {Ter }}(n) . \zeta_{\text {Air }}^{\text {Res }}$ can be computed directly from residual airborne gravity disturbances at flight altitude in one step using the generalized Hotine's integral with spectral weights $W_{\text {Air }}(n)$. $\zeta_{\text {Ter }}^{\text {Ref }}$ and $\zeta_{\text {Air }}^{\text {Ref }}$ are computed from the reference gravity model by spherical harmonic synthesis using spectral weights $W_{\text {Ter }}(n)$ and $W_{\text {Air }}(n)$, respectively. $\zeta^{R T M}$ is computed using the formula of rectangular prism for the RTM effects of height anomaly (Frosberg 1984; Nagy et al. 2000). Detailed formulas for the computation of above terms are referred to Eqs. (1-7) in Jiang and Wang (2016). Note that the gravity disturbance is used for airborne gravity data, because geodetic heights of the aircraft can be accurately known from the onboard GPS kinematic positioning.

The key problem for a decent geoid solution from the combination of satellite gravity model, terrestrial and airborne gravity data is to determine the proper spectral weights of each dataset, $W_{\text {Sat }}(n), W_{\text {Ter }}(n)$ and $W_{\text {Air }}(n)$. The spectral weights of each dataset can be derived from the corresponding error degree variances using the condition of least squares residuals (Wenzel 1982; Sjöberg 1981). For Colorado geoid experiment, we selected the KTH (Royal Institute of Technology, Sweden) error degree variance estimation method, which applies the white and colored noise models to estimate the error degree variances of terrestrial and airborne gravity data (Sjöberg 1986; Ågren 2004). Formulas for spectral weight determination and $\mathrm{KTH}$ error degree variance estimation are referred to Eqs. (10-13 and 24-28) in Jiang and Wang (2016).

As the Colorado geoid experiment is standardized to be consistent with the IHRS definition, and geodetic reference system 1980 (GRS80, Moritz 2000) is adopted as the reference ellipsoid, and the zero-degree term of height anomaly is computed by

$$
\zeta_{0}=\frac{G M-G M_{G R S 80}}{r_{P} \bullet \gamma_{Q}}-\frac{W_{0}-U_{0}}{\gamma_{Q}},
$$

where $G M$ and $G M_{G R S 80}$ are the geocentric gravitational constants adopted by the IHRS and GRS80, $W_{0}$ is the IHRS reference gravity potential and $U_{0}$ is the normal gravity potential on GRS80 ellipsoid, $r_{P}$ is the geocentric radial distance of the computation point, and $\gamma_{Q}$ is the normal gravity of the corresponding point on the telluroid.

The geoid--quasigeoid separation term is computed by (Flury and Rummel 2009)

$$
\begin{aligned}
& \Delta_{F R}=N-\zeta=\Delta g^{B O} \frac{H}{\bar{\gamma}}+\frac{1}{\bar{\gamma}}\left(V_{P_{0}}^{T O P}-V_{P}^{T O P}\right), \\
& \Delta g^{B O}=\Delta g-2 \pi \mathrm{G} \rho_{0} \mathrm{H}+\mathrm{g}_{\mathrm{P}}^{\mathrm{TC}},
\end{aligned}
$$

where $\Delta g^{B O}$ is the refined Bouguer gravity anomaly, $H$ is the orthometric height, $\bar{\gamma}$ is the mean normal gravity, and $V_{P}^{T O P}$ and $V_{P_{0}}^{T O P}$ are the gravitational potentials of the topographic masses evaluated at the computation point and its projection point on the geoid. $G$ is the constant of gravitation, $\rho_{0}$ is the average density of topographic masses, and $g_{P}^{T C}$ is the terrain correction evaluated at the computation point. Equation (4) is an extension of the well-known approximation of the geoid-quasigeoid separation term in Heiskanen and Moritz (1967, Eqs. (8-102))

$$
\Delta_{H M}=N-\zeta=\Delta g^{B O} \frac{H}{\bar{\gamma}}
$$

As a summary, the procedure of gravimetric geoid modeling by spectrally combining satellite gravity model, terrestrial and airborne gravity data is shown in Fig. 1.

\section{The Colorado geoid experiment and the data}

The reason for selecting Colorado as the experiment area was that it is the test area of the geoid slope validation survey 2017 (GSVS17) of NGS, where aboundant terrestrial, airborne gravity, GPS leveling and other terrestrial survey data are available. GSVS17 is the third survey after GSVS11 (Smith et al. 2013) and GSVS14 (Wang et al. 2017). The purpose of GSVSs is to evaluate the reachable accuracy of gravimetric geoid models and quantify the contribution of airborne gravity data of the 'Gravity for the Redefinition of the American Vertical Datum' (GRAV-D) project to the improvement of geoid models. While GSVS11 was performed over a low and flat topographic area in Texas and GSVS14 took place in Iowa in an area with moderate topography but significant gravity variation, GSVS17 selected a rough topographic area in Colorado which made it the most challenging case for geoid modeling among the three GSVS tests. Figure 2 shows the topography of the experiment area based on the shuttle radar topography mission (SRTM) DEM data (Farr et al. 2007) and the GSVS17 terrestrial survey traverse. The average, minimum and maximum topographic elevation of this area is $1733 \mathrm{~m}, 314 \mathrm{~m}$ and $4385 \mathrm{~m}$, respectively. 


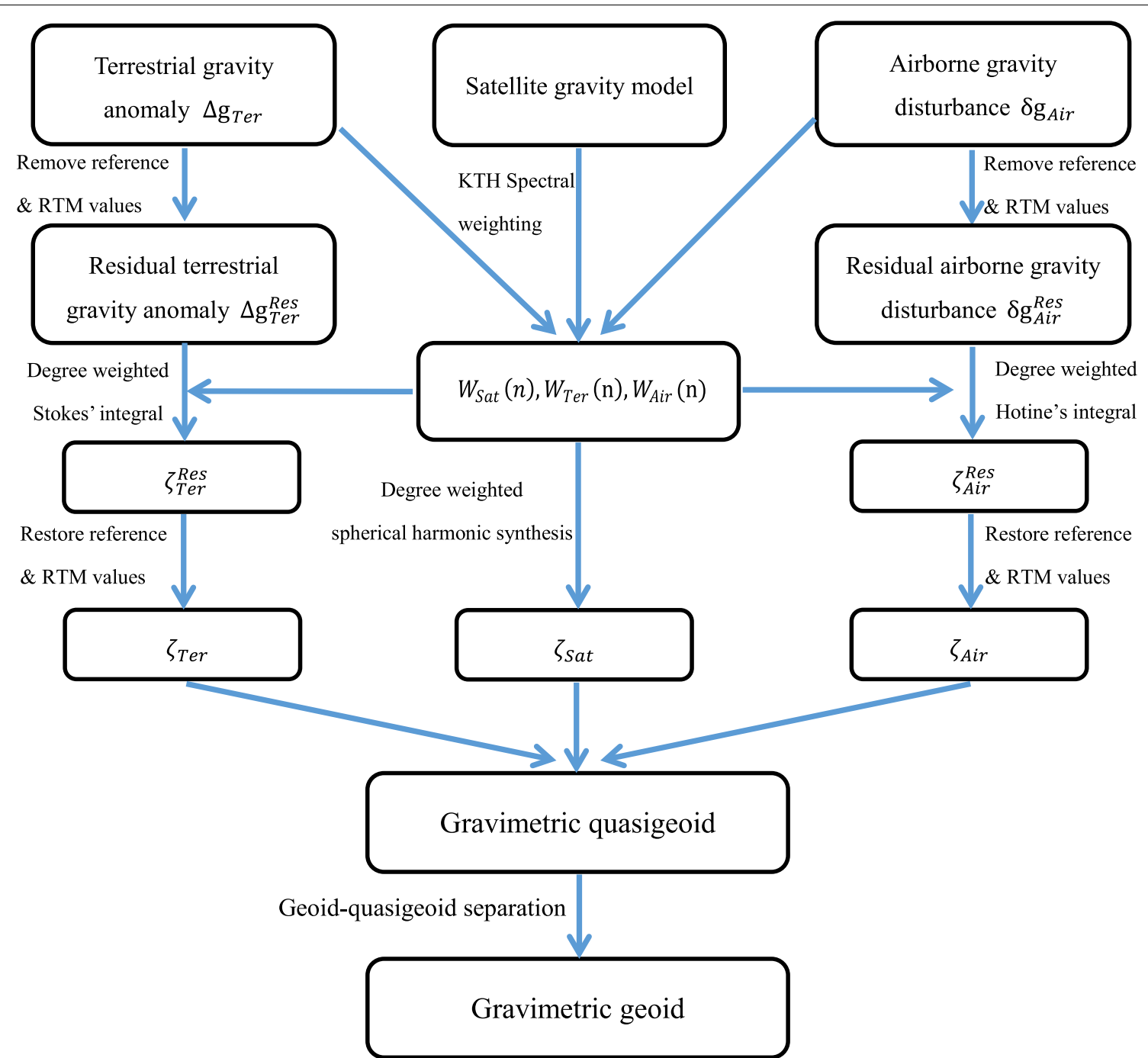

Fig. 1 Procedure of gravimetric geoid modeling based on the combination of satellite gravity model, terrestrial and airborne gravity data

Terrestrial gravity observations along with orthometric heights at 59,303 points in the area bounded by $35^{\circ} \leq \varphi \leq 40^{\circ}$ and $250^{\circ} \leq \lambda \leq 258^{\circ}$ were extracted from the gravity database of NGS. Over the area bounded by $34.5^{\circ} \leq \varphi \leq 38.8^{\circ}$ and $250.8^{\circ} \leq \lambda \leq 258.6^{\circ}$, the GRAV-D airborne gravity data were collected using the Micro-g LaCoste TAGS (turn-key airborne gravimetry system). The aircraft flown in the nominal ground speed of $460 \mathrm{~km} / \mathrm{h}$ at the average altitude of $6186 \mathrm{~m}$ (geodetic height). For the differential kinematic positioning of the aircraft, two ground static GPS stations were set up within the area. GPS data were collected and then processed based on the reference frame of GRS80 and ITRF2008 (international terrestrial reference frame 2008). The average precision of horizontal and vertical position of the aircraft is $5.2 \mathrm{~cm}$ and $8.7 \mathrm{~cm}$ (95\% confidence interval), respectively. There are 49 west-east going data lines consisting of 283,716 observations and 7 north-south going cross lines, forming 269 crossover points. The designed spacing of adjacent data lines is $10 \mathrm{~km}$ and that of adjacent cross lines is $80 \mathrm{~km}$. The total RMS (root mean square) error of the crossover discrepancies is estimated to be $2.2 \mathrm{mGal}$. An along track timedomain Gaussian filter of $120 \mathrm{~s}$ was applied to reduce the high-frequency noises in the airborne gravity data (GRAV-D Science Team 2017a, 2017b, 2017c).

To validate the gravimetric geoid models, NGS provided historic GPS leveling data at 194 benchmarks for the area bounded by $36^{\circ} \leq \varphi \leq 39^{\circ}$ and $251^{\circ} \leq \lambda \leq 257^{\circ}$. The error budget of these GPS leveling measured geoid heights is estimated to be around $3 \mathrm{~cm}$ (Wang et al. 2020), which makes them the reliable independent data for the preliminary validation and analysis of the gravimetric geoid models. Note that the 


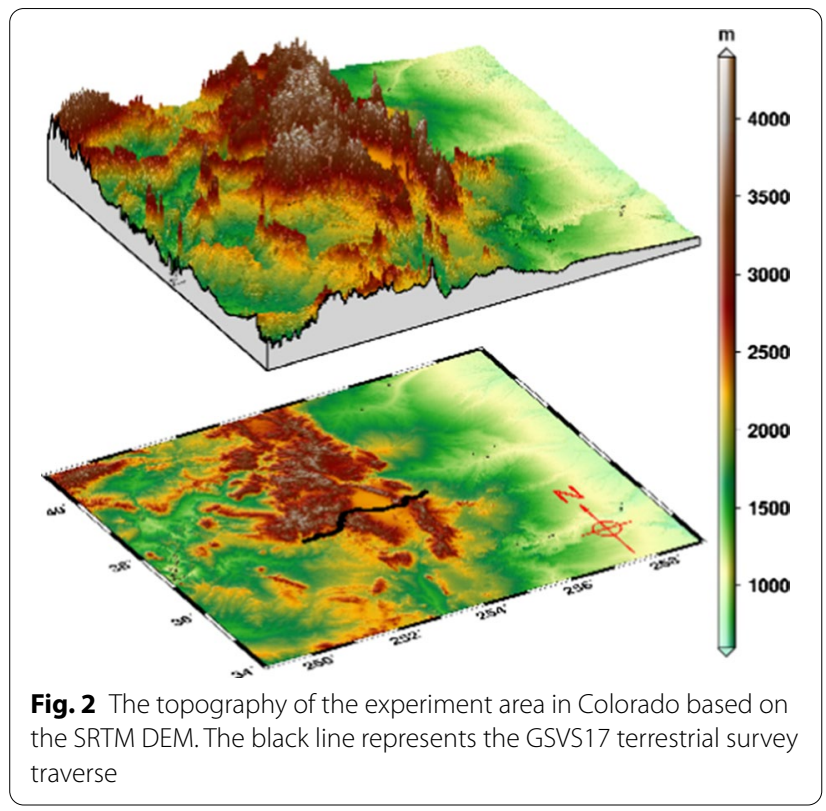

orthometric heights in the NAVD88 (the North American Vertical Datum of 1988) were obtained following the Helmert orthometric hypotheses (Zilkoski 1992). If the rigorous geoid-quasigeoid separation $\Delta_{F R}$ in Flury and Rummel (2009) is used, the Helmert orthometric heights should be corrected to the rigorous orthometric heights using consistent correction. From HofmannWellenhof and Moritz (2005, Eqs. 4-31), Santos et al. (2006, Eq. 15) and Flury and Rummel (2009, Eq. 18-19), we obtained the correction $\varepsilon^{H}$ as

$$
\begin{aligned}
& \varepsilon^{H}=-\frac{H}{\bar{g}}\left(\bar{g}-\bar{g}^{H}\right), \\
& \bar{g}^{H}=g_{P}+0.0424 \frac{m G a l}{m} H, \\
& \bar{g}-\bar{g}^{H}=\frac{1}{H}\left(V_{P_{0}}^{T O P}-V_{P}^{T O P}\right)+g_{P}^{T C} \\
& H^{O}=H+\varepsilon^{H},
\end{aligned}
$$

where $\bar{g}$ is the integral-mean value of gravity along the plumb line between the geoid and the Earth surface, $\bar{g}^{H}$ is the Helmert approximation of the mean gravity along the plumb line, $H$ is the Helmert orthometric height, $H^{O}$ is the rigorous orthometric height, and $g_{P}$ is the gravity at the surface point. In the Colorado case, the gravity values at the 194 benchmarks were interpolated from the terrestrial gravity data.
The spatial distribution of terrestrial gravity points, airborne gravity survey lines, and historic GPS leveling benchmarks are plotted in Fig. 3. The statistics of the terrestrial gravity anomalies and the GRAV-D airborne gravity disturbances in this area are listed in Table 1.

\section{Gravimetric geoid computation}

\section{General parameters and procedures}

For the computation and analysis of gravimetric geoid models, the following general parameters and procedures were adopted:

1. Geocentric gravitational constant $(G M): 3.986004$ $415 \times 10^{14} \mathrm{~m}^{3} \mathrm{~s}^{-2}$.

Nominal mean angular velocity of the Earth $(\omega)$ : $7.292115 \times 10^{-5} \mathrm{rad} \mathrm{s}^{-1}$.

Conventional reference gravity potential value $\left(W_{0}\right)$ according to the IHRS definition: 62636853.4 $\mathrm{m}^{2} \mathrm{~s}^{-2}$.

Average density of topographic masses $\left(\rho_{0}\right)$ : $2670 \mathrm{~kg} \mathrm{~m}^{-3}$.

2. Geographic limits of the computed geoid models: $35.5^{\circ} \leq \varphi \leq 39.5^{\circ}$ and $250.5^{\circ} \leq \lambda \leq 257.5^{\circ}$. Grid resolution: $1^{\prime} \times 1^{\prime}$.

3. Geoid computations were performed in the tidefree system. GRS80 was used as the reference ellipsoid, and the conventional constants are referred to Moritz (2000).

4. Atmospheric corrections were applied on the terrestrial and airborne gravity data using the formula (Dimitrijevich 1987, p. 4):

$$
\begin{aligned}
& \varepsilon_{\text {Atc }}=0.87 \cdot e^{-0.116 \bullet H^{1.047}} m \text { GalifH } \geq 0, \\
& \varepsilon_{\text {Atc }}=0.87 m \text { GalifH }<0
\end{aligned}
$$

where the orthometric height $H$ in $\mathrm{km}$.

5. After removing reference gravity values and RTM effects on gravity, the residual terrestrial gravity anomalies and residual airborne gravity disturbances were gridded into $1^{\prime} \times 1^{\prime}$ grid using the program GEOGRID (Tscherning et al. 1991), separately. The maximum degree of the terrestrial gravity contribution was set to be 10,800 corresponding to the $1^{\prime}$ grid spacing of terrestrial data.

6. The radius of spherical cap was empirically chosen as $1^{\circ}$ for Stokes' and Hotine's integration. Geoid models based on the integration radius of $0.5^{\circ}, 1^{\circ}, 1.5^{\circ}$ and $2^{\circ}$ were tested against the GPS leveling data, among which the $1^{\circ}$ radius yielded the best agreement. 


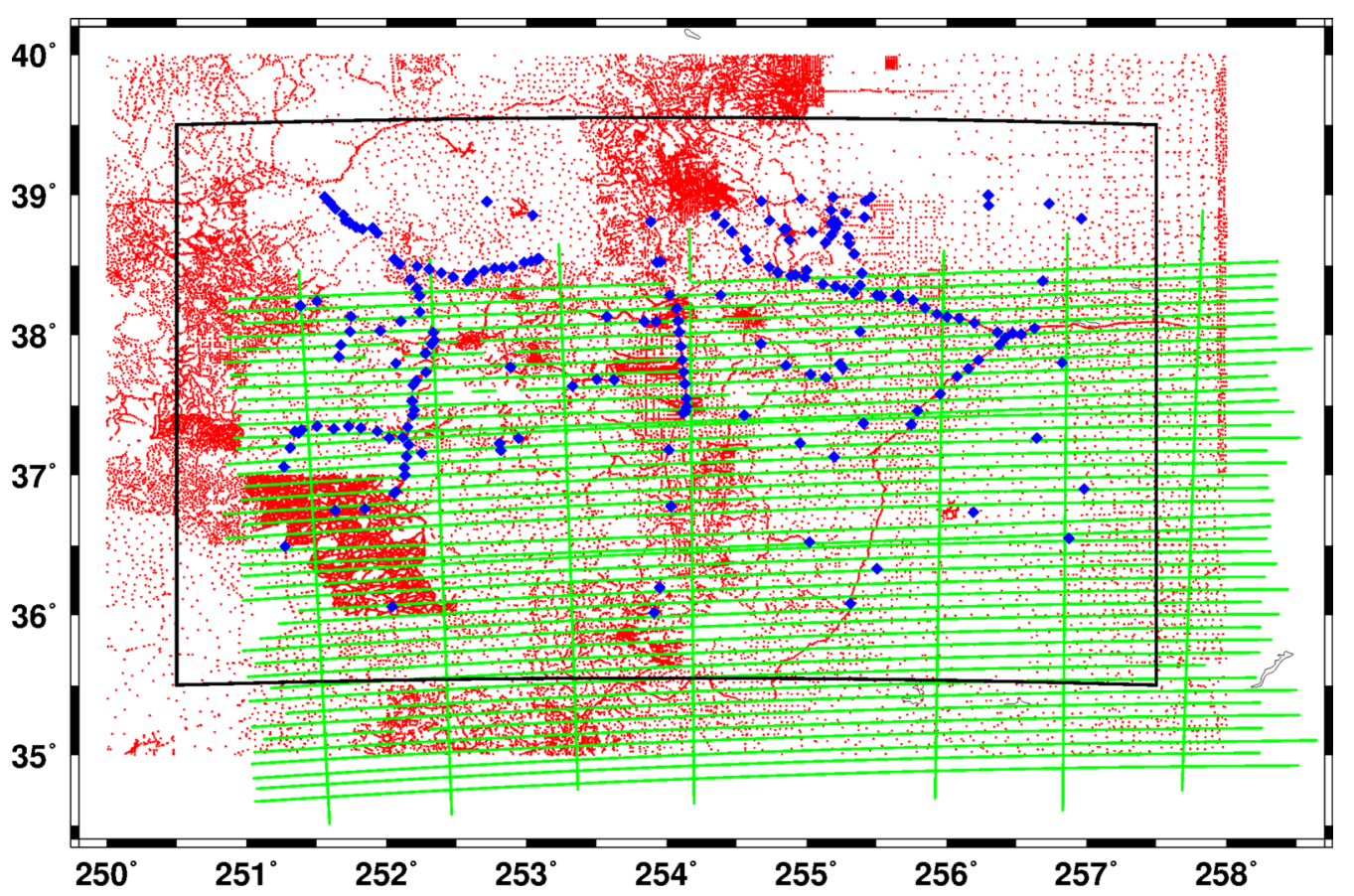

Fig. 3 Distribution of terrestrial, airborne gravity and historic GPS leveling data in Colorado. Red points represent terrestrial gravity observations. Green lines represent GRAV-D airborne gravity data. Blue diamonds represent historic GPS leveling benchmarks. The computation area is bounded by the black rectangular

Table 1 Statistics of terrestrial gravity anomalies and airborne gravity disturbances (unit: $\mathrm{mGal}$ )

\begin{tabular}{lllll}
\hline Data & Min & Max & Mean & SD \\
\hline Terrestrial gravity anomaly & -164.8 & 212.6 & 6.1 & 38.1 \\
Airborne gravity disturbance & -45.2 & 123.7 & 6.1 & 29.0 \\
\hline
\end{tabular}

7. The RTM effects on gravity were computed using the $3^{\prime \prime} \times 3^{\prime \prime}$ SRTM v4.1 DEM data and a mean DEM by the program TC (Forsberg 1984) with the integration radius of $100 \mathrm{~km}$, and the resolution of mean DEM depends on the truncation degree of reference degree model.

8. For the KTH error degree variance estimation, the error degree variances of satellite gravity models were computed using their error coefficients. Considering that terrestrial gravity data errors are unknown and the RMS of the crossover discrepancies of airborne gravity data is $2.2 \mathrm{mGal}$ (GRAVD Science Team 2017c), we empirically assigned $\sigma_{w}=3 m G a l, \sigma_{c}=1 m G a l$ for the terrestrial gravity anomalies and $\sigma_{w}=1.5 \mathrm{mGal}, \sigma_{c}=0.5 \mathrm{mGal}$ for the airborne gravity disturbances, where $\sigma_{w}$ and $\sigma_{c}$ are the standard derivation (SD) of the white and colored noise, respectively. The other criterion for choosing $\sigma_{w}$ and $\sigma_{c}$ was that they yielded reasonable and realistic spectral weights for satellite gravity model, terrestrial and airborne gravity data (Figs. 4 and 5). The Nyquist frequencies of terrestrial and airborne gravity data were set to be $N_{Q}^{T e r}=10800$ and $N_{Q}^{\text {Air }}=2000$, respectively.

9. Following the procedure in Fig. $1, \zeta_{\text {Sat }}$ was derived from the spectral weighted potential coefficients of satellite gravity models, $\zeta_{\mathrm{Ter}}$ was computed from the terrestrial gravity grid using the degree weighted Stokes' integral and $\zeta_{\text {Air }}$ was computed directly from the airborne gravity grid at flight altitude using the degree weighted Hotine's integral. In this way, the satellite gravity model, terrestrial and airborne gravity data were spectrally combined to obtain the geoid models.

\section{Combination of satellite gravity model and terrestrial gravity data}

As the first part of the Colorado geoid modeling experiment, gravimetric geoid models are computed from the combination of satellite gravity model and terrestrial gravity data, which is the classical mode for data combination in areas where airborne gravity data are not available. Thus the terms for airborne gravity data in the 

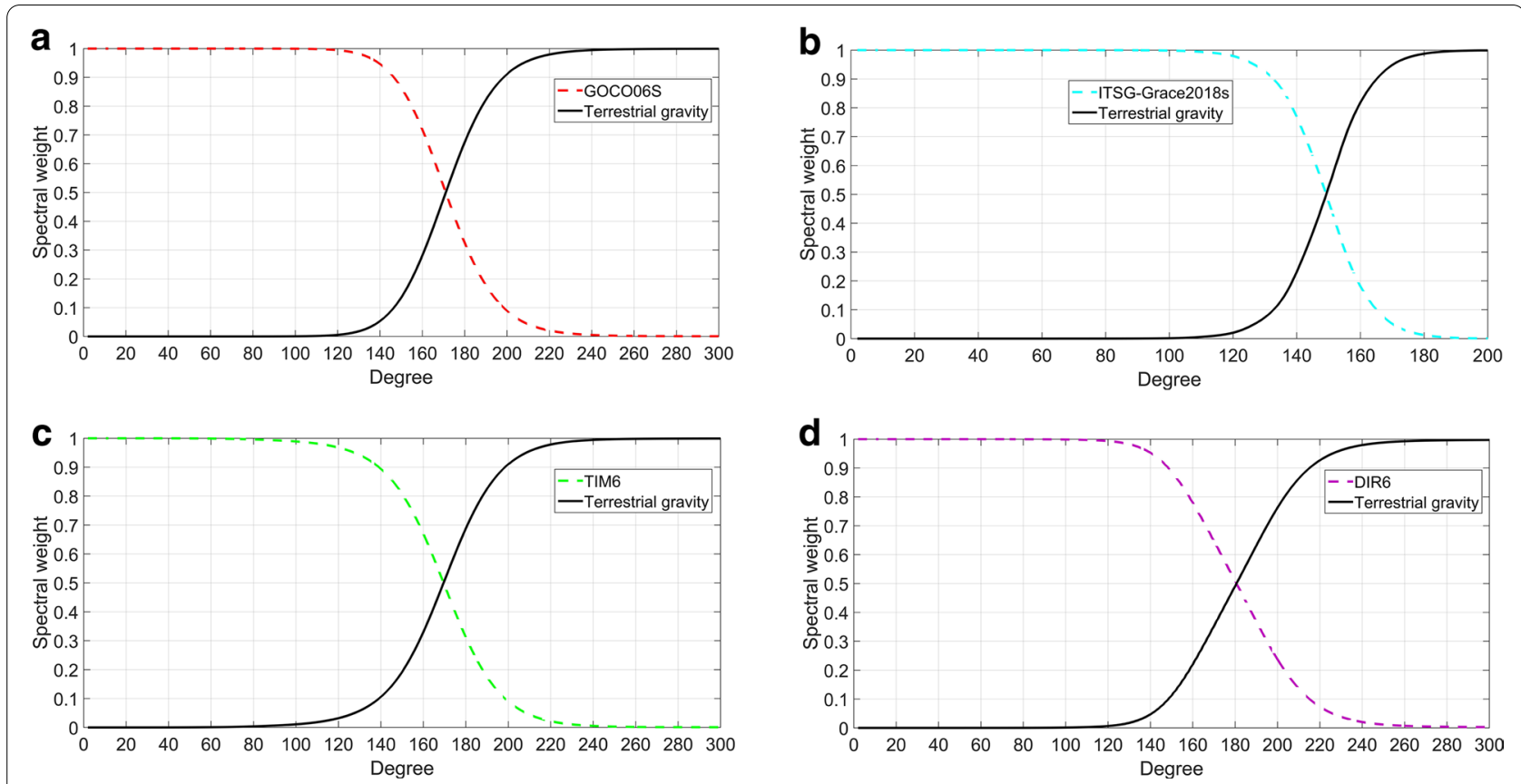

Fig. 4 Spectral weights of satellite gravity models and terrestrial gravity data. The satellite gravity models are: a GOCO06S. b ITSG-Grace2018s. c TIM6. d DIR6

equations of Sect. (2) should not be considered in the computation.

\section{Choice of satellite gravity model}

There are dozens of satellite gravity models archived at the International Centre for Global Earth Models (ICGEM, Barthelmes et al. 2016; Ince et al 2019), which were developed using different sources of satellite data. To analyze the performance of different satellite gravity models and select the suitable one for data combination, four representative satellite gravity models including GOCO06S up to degree and order 300 (Kvas et al. 2019), ITSG-Grace2018s up to degree and order 200 (Mayer-Gürr et al. 2018), GO_CONS_GCF_2 TIM_R6 up to degree and order 300 (TIM6, Brockmann et al. 2019) and GO_CONS_GCF_2_DIR_R6 up to degree and order 300 (DIR6, Förste et al. 2019) were used and compared. GOCO06S is based on more than 1,160,000,000 observations from 19 satellites including GOCE (Drinkwater et al. 2003), GRACE (Tapley et al. 2004), kinematic satellite orbit and satellite laser ranging (SLR). ITSG-Grace2018s is a GRACE-only gravity field model estimated from 162 months of data in the time span from 2002-04 to 2017-06. TIM6 is purely modeled from GOCE data using the time-wise approach. DIR6 is derived from the combination of GOCE-SGG with GRACE and SLR tracking data using the direct approach.
Figure 4 shows the spectral weights of terrestrial gravity data and each satellite gravity model, respectively. The contributions of terrestrial gravity data start at degree 126, 115, 99 and 125 for the combination with GOCO06S, ITSG-Grace2018s, TIM6 and DIR6. The spectral weights of terrestrial gravity data are equal to those of each satellite gravity model at degree 171, 149, 170 and 181. At these degrees, the satellite models and terrestrial gravity data have equal contribution in the data combination. After these degrees, the spectral weights of four satellite gravity models quickly decrease to zero at degree 231, 182, 231 and 253, while those of terrestrial gravity data increase to 1 symmetrically.

To compare the performance of the four satellite gravity models in the data combination, four gravimetric geoid models were computed by combining terrestrial gravity data with GOCO06S, ITSG-Grace2018s, TIM6 and DIR6, respectively. EGM2008 model up to degree and order 2190 was used as the reference gravity model. Statistics of the differences between the four geoid models and the GPS leveling measured geoid heights are shown in Table 2. It turns out that the biases and standard deviations of differences between the four geoid models and the GPS leveling measured geoid heights agree with each other in millimeter level, though the four satellite gravity models are derived from different sources of dataset. It seems that each satellite model is suitable for the data combination. Considering the multiple source of satellite 
Table 2 Statistics of the differences between the gravimetric geoid models derived by combing satellite gravity models with terrestrial gravity and the GPS leveling measured geoid heights (unit: $\mathrm{m}$ )

\begin{tabular}{lllll}
\hline Satellite gravity model & Min & Max & Mean & SD \\
\hline GOCO06S & 0.703 & 1.029 & 0.864 & 0.058 \\
ITSG-Grace2018s & 0.713 & 1.027 & 0.869 & 0.058 \\
TIM6 & 0.701 & 1.035 & 0.863 & 0.059 \\
DIR6 & 0.695 & 1.051 & 0.867 & 0.060 \\
\hline
\end{tabular}

data and the time span and amount of observation data used in the modeling of GOCO06S, it was selected as the satellite gravity model to be combined with terrestrial and airborne gravity data for geoid modeling.

\section{Choice of reference gravity model}

Due to the limited coverage of terrestrial gravity data, reference gravity model is applied in a remove-compute-restore fashion to account for the contribution outside the terrestrial data domain. To select the proper reference gravity model and its truncation degree, three high-degree gravity field models up to degree and order 2190, EGM2008, EIGEN-6C4 (Förste et al. 2014) and XGM2019 (Zingerle et al. 2019) were compared. Table 3 shows the statistics of the differences between the gravimetric geoid models based on the three reference gravity models and the GPS leveling measured geoid heights; each reference model was truncated to degree 2190, 1080 and 720 , respectively. The geoid models were computed by combining the GOCO06S model and terrestrial gravity data. The comparison results suggest that the three reference gravity models yield almost identical geoid model accuracy for the same truncation degree. The optimal degree of truncation for each reference gravity model is 2190 , which results in the best accuracy of $5.8 \mathrm{~cm}$ in terms of the standard deviation of the differences. Lower truncation degree causes larger truncation errors of the gravity field, which will degrade the accuracy of geoid solution. The closeness of the results in Tables 2 and 3 demonstrates the reliability and stability of the spectral combination method for geoid computation; no matter which satellite gravity model or reference gravity model was used in the data combination, the results agree in millimeter level.

In consideration of the two facts: (1) EIGEN-6C4 used EGM2008-derived gravity anomalies over continents (Förste et al. 2014) and XGM2019 used a global $15^{\prime} \times 15^{\prime}$ gravity anomaly data grid provided from the database of NGA (National Geospatial-Intelligence Agency) of the USA (Zingerle et al. 2019), which is nearly the same terrestrial dataset for the EGM2008 model. (2) EGM2008 model adopted much less satellite observations compared with EIGEN-6C4 and XGM2019, and no GOCE data were used. It has the minimum data overlap with the satellite gravity model GOCO06S, which is an advantage for the explicit combination of GOCO06S with terrestrial and airborne gravity data in this case. We selected EGM2008 up to degree and order 2190 as the reference gravity model for geoid computation.

\section{Combination of satellite gravity model, terrestrial and airborne gravity data}

Because of the thriving of airborne gravity campaigns in many countries or regions, the combination of satellite gravity model, terrestrial and airborne gravity data are expected to be the main data combination mode for regional geoid determination. In this section, the geoid models are computed by spectrally combining GOCO06S model, terrestrial and GRAV-D airborne gravity data and then validated using the GPS leveling measured geoid heights.

\section{Spectral weights of satellite gravity model, terrestrial and airborne gravity data}

The spectral weights of satellite gravity model GOCO06S, terrestrial and GRAV-D airborne gravity data are plotted in Fig. 5. GOCO06S model takes nearly full weight in the data combination below degree 114, and after that the weight rapidly reduces to zero around degree 217 . Starting from the degree of 139 , the spectral weight of airborne gravity data quickly rises and reaches the maximum value of 0.63 until degree 204, then slowly reduces

Table 3 Statistics of the differences between the gravimetric geoid models based on different reference gravity models and the GPS leveling measured geoid heights (unit: $\mathrm{m}$ )

\begin{tabular}{|c|c|c|c|c|c|c|}
\hline \multirow[t]{2}{*}{ Reference gravity model } & \multicolumn{2}{|c|}{ To d/o 2190} & \multicolumn{2}{|c|}{ To d/o 1080} & \multicolumn{2}{|c|}{ To d/o 720} \\
\hline & Mean & SD & Mean & SD & Mean & SD \\
\hline EGM2008 & 0.864 & 0.058 & 0.883 & 0.067 & 0.882 & 0.072 \\
\hline EIGEN-6C4 & 0.868 & 0.059 & 0.883 & 0.068 & 0.882 & 0.073 \\
\hline XGM2019 & 0.867 & 0.058 & 0.884 & 0.068 & 0.882 & 0.072 \\
\hline
\end{tabular}

$\mathrm{d} / \mathrm{o}$ represents the truncation degree and order of Earth gravity models 


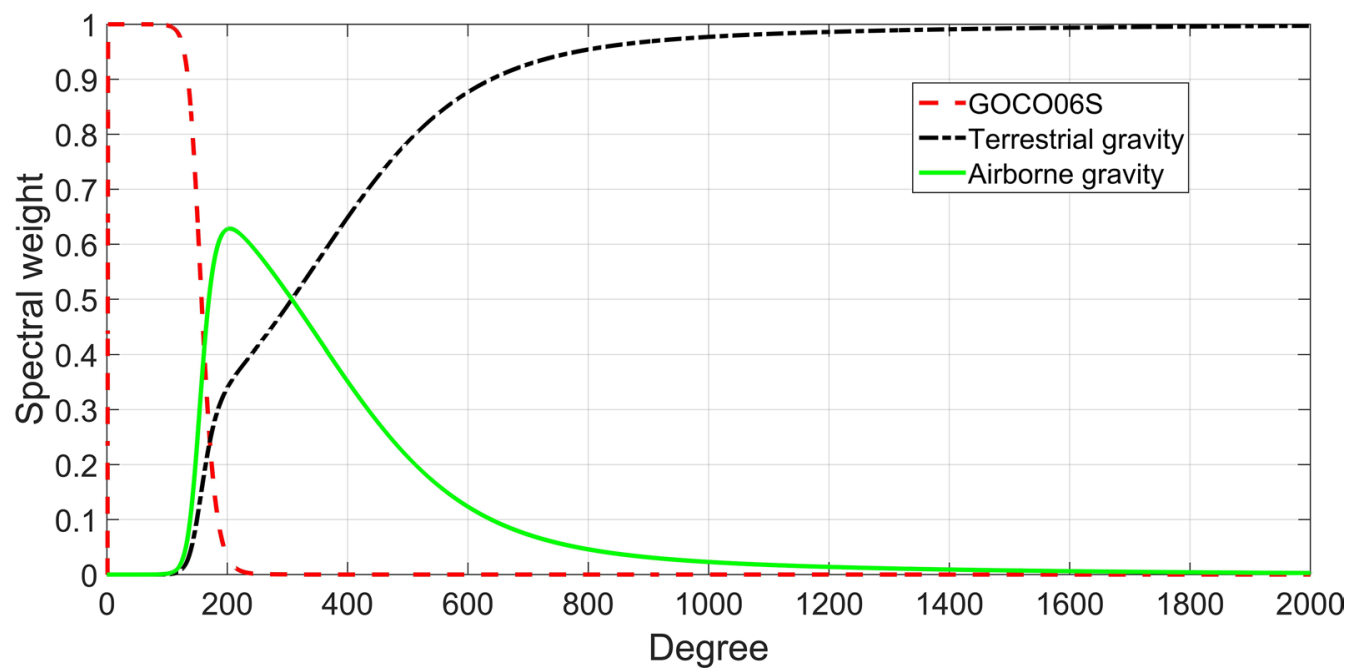

Fig. 5 Spectral weights of satellite gravity model GOCO06S, terrestrial and airborne gravity data

to zero around degree 1355 . The main contributions of airborne gravity data concentrate at the spectral band from degree 148 to $512\left(W_{A i r}(n) \leq 0.2\right)$, and the airborne data weight more than the terrestrial data in the data combination below degree 308. After the degree of 1000, the contributions of terrestrial gravity data are dominant and those of airborne data can be neglected. Note that the along track time-domain Gaussian filter of $120 \mathrm{~s}$ could not remove all the airborne data noises. The characteristic of decreasing spectral weights of airborne gravity data at medium and high degrees is crucial for suppressing the high-frequency data noises, so that the one-step geoid computation directly from the airborne gravity data at flight altitude via degree weighted Hotine's integral can be stabilized.

\section{Gravimetric geoid validation}

The statistics of the differences between gravimetric geoid models based on different data combination modes and GPS leveling measured geoid heights are shown in Table 4, and the geoid height differences are plotted in Fig. 6. The differences for the geoid heights computed from EGM2008, EIGEN-6C4 and XGM2019 are also included for comparison. EGM2008 performs better than EIGEN-6C4 and XGM2019 in the experiment area. In comparison with EGM2008 model, the accuracy of the geoid model derived from the combination of GOCO06S model and terrestrial gravity data is slightly improved by $3 \mathrm{~mm}$ in terms of the standard deviation, and the two models show a $1.7 \mathrm{~cm}$ discrepancy in the bias. Since both geoid models are based on the exactly same terrestrial gravity dataset in this area, the differences in their performance can be attributed to the better satellite gravity data
Table 4 Statistics of the differences between the gravimetric geoid models based on different data combination modes and the GPS leveling measured geoid heights (unit: $m$ )

\begin{tabular}{lllll}
\hline Gravimetric geoid model & Min & Max & Mean & SD \\
\hline EGM2008 & 0.625 & 1.008 & 0.847 & 0.061 \\
EIGEN-6C4 & 0.575 & 0.999 & 0.851 & 0.067 \\
XGM2019 & 0.563 & 1.034 & 0.836 & 0.075 \\
GOCO06S + Terrestrial & 0.703 & 1.029 & 0.864 & 0.058 \\
GOCO06S + Terrestrial + Airborne & 0.710 & 1.048 & 0.863 & 0.053 \\
\hline
\end{tabular}

used in the latter and the difference between the local and global modeling method for gravity field refinement. After the addition of GRAV-D airborne gravity data, the geoid model accuracy is improved from $5.8 \mathrm{~cm}$ to $5.3 \mathrm{~cm}$ in terms of the standard deviation. Considering the rough topography in this area and the error budget of the historic GPS leveling data, this accuracy level is promising. Figure 7 shows the gravimetric geoid model based on the combination of GOCO06S model, terrestrial and GRAV$\mathrm{D}$ airborne gravity data. The $86.3 \mathrm{~cm}$ bias between this gravimetric geoid model and the GPS leveling measured geoid heights is caused by the different potential values $\left(W_{0}\right)$ adopted by the IHRS and the NAVD88.

\section{Geoid-quasigeoid separation}

For geoid determination at centimeter accuracy level in the Colorado experiment area with high, rugged and geologically complex topography, the transformation from height anomalies to geoid heights needs to be dealt with carefully. We used the rigorous formula (Eq. 4) derived by Flury and Rummel (2009) to compute the 


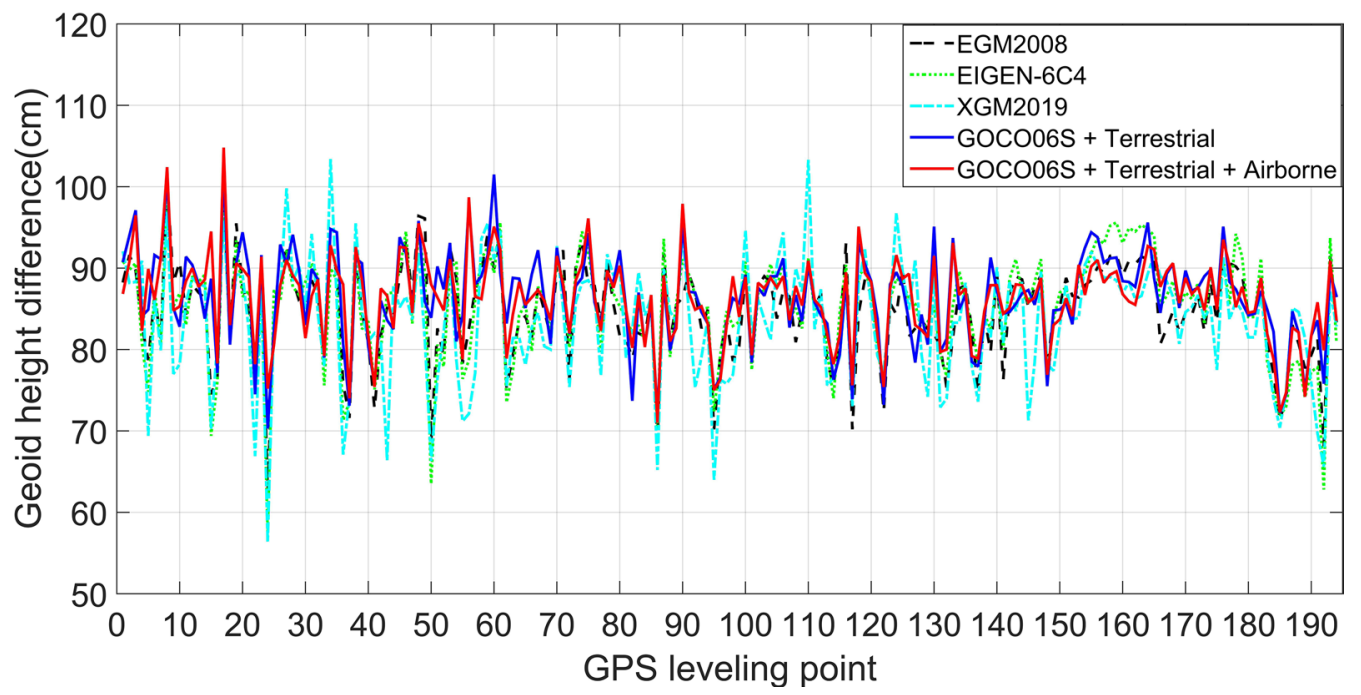

Fig. 6 Differences between the gravimetric geoid models based on different data combination modes and the GPS leveling measured geoid heights. Results for EGM2008, EIGEN-6C4 and XGM2019 are included

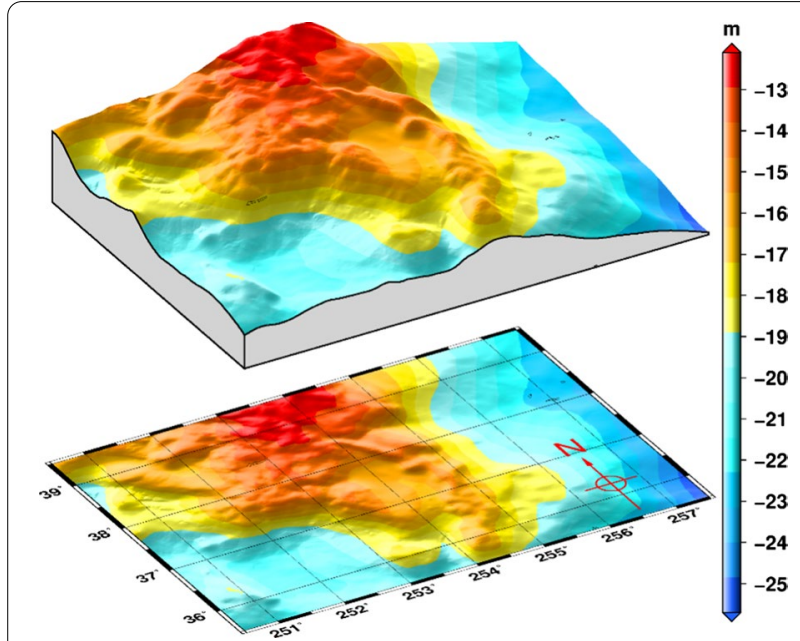

Fig. 7 Gravimetric geoid model derived from the combination of satellite gravity model GOCO06S, terrestrial and GRAV-D airborne gravity data

geoid-quasigeoid separation term. This approach rigorously accounts for the contribution of the attraction of topographic masses to the mean gravity along the plumb line; it differs from the approximation (Eq. 6) of Heiskanen and Moritz (1967) in the term of $\left(V_{P_{0}}^{T O P}-V_{P}^{T O P}\right) / \bar{\gamma}$. The geoid-quasigeoid separations based on both approaches were computed from the $3^{\prime \prime} \times 3^{\prime \prime}$ SRTM DEM data using the rectangular prism formulae (Nagy et al. 2000) with an integration radius of $100 \mathrm{~km}$. Statistics of the geoid-quasigeoid separations $\Delta_{H M}, \Delta_{F R}$ and their difference $\left(V_{P_{0}}^{T O P}-V_{P}^{T O P}\right) / \bar{\gamma}$ are
Table 5 Statistics of the geoid-quasigeoid separations (unit: $\mathbf{m}$ )

\begin{tabular}{llcll}
\hline $\begin{array}{l}\text { Geoid-quasigeoid } \\
\text { separation }\end{array}$ & Min & Max & Mean & SD \\
\hline$\Delta_{H M}$ & -1.542 & -0.138 & -0.496 & 0.235 \\
$\Delta_{F R}$ & -1.398 & -0.140 & -0.496 & 0.229 \\
$\left(V_{P_{0}}^{T O P}-V_{P}^{T O P}\right) / \bar{\gamma}$ & -0.123 & 0.181 & -0.000 & 0.019 \\
\hline
\end{tabular}

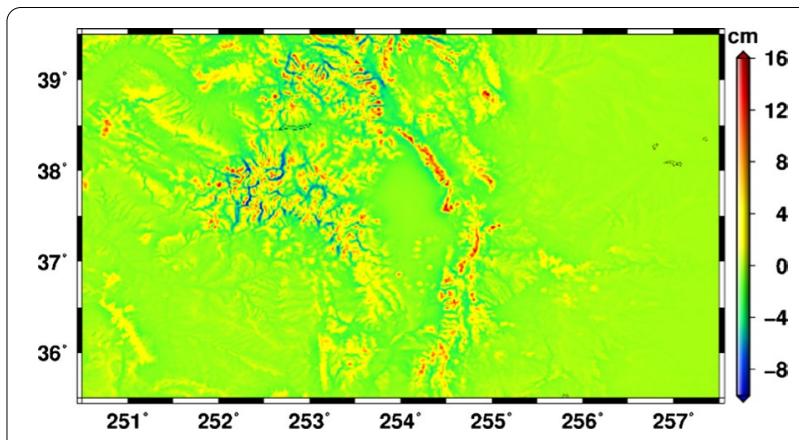

Fig. 8 Differences between $\Delta_{F R}$ and $\Delta_{H M}\left(\left(V_{P_{0}}^{T O P}-V_{P}^{T O P}\right) / \bar{\gamma}\right)$

summarized in Table 5, and $\left(V_{P_{0}}^{T O P}-V_{P}^{T O P}\right) / \bar{\gamma}$ at the computation grids are shown in Fig. 8. Two geoid models were computed from the combination of GOCO06S model, terrestrial and airborne gravity data, one with the rigorous geoid-quasigeoid separation $\Delta_{F R}$ and the other with the approximation $\Delta_{H M}$. Statistics of the differences between the geoid models and the GPS leveling measured geoid heights are given in Table 6. Comparison 
results show that the accuracy of geoid model based on $\Delta_{F R}$ is $8.6 \%$ better than that of geoid model based on $\Delta_{H M}$, demonstrating the necessity of applying the rigorous modeling of geoid-quasigeoid separation rather than using the approximation in this mountainous area.

\section{Contribution of airborne gravity data}

To quantify the contribution of airborne gravity data to geoid modeling in the combination with terrestrial gravity data of different spatial distribution and density, terrestrial data points were resampled at the spacing of $5 \mathrm{~km}$, $10 \mathrm{~km}, 15 \mathrm{~km}, 20 \mathrm{~km}, 25 \mathrm{~km}, 30 \mathrm{~km}, 35 \mathrm{~km}$ and $40 \mathrm{~km}$ on the basis of the original data. Two groups of gravimetric geoid models were computed; group A consists of nine geoid models based on the combination of GOCO06S model, airborne and terrestrial gravity data with original spacing and the spacing of $5 \mathrm{~km}, 10 \mathrm{~km}, 15 \mathrm{~km}, 20 \mathrm{~km}$, $25 \mathrm{~km}, 30 \mathrm{~km}, 35 \mathrm{~km}$ and $40 \mathrm{~km}$, respectively, while group $\mathrm{B}$ includes the nine counterparts derived from the combination of the GOCO06S model and these terrestrial data. The changes of geoid heights contributed from airborne gravity data are shown in Fig. 9, which are the differences between the corresponding geoid models with and without the airborne data (group A-group B), and the statistics of the geoid height changes are listed in Table 7. In the cases of terrestrial gravity, the point spacings are less than or equal to $15 \mathrm{~km}$, and the magnitude and characteristics of the geoid height changes are very close with each other, exhibiting short wavelength features. In the cases of terrestrial point spacing of $20 \mathrm{~km}, 25 \mathrm{~km}, 30 \mathrm{~km}$, $35 \mathrm{~km}$ and $40 \mathrm{~km}$, the magnitudes of geoid height differences increase with the widening of the terrestrial data spacing, and the medium wavelength dominant characteristics of the changes in geoid heights behave quite differently from one to another.

To evaluate the contribution of airborne gravity data to the improvement of geoid model accuracy in different topographic areas, we divided the 194 GPS leveling benchmarks into two groups, with 90 benchmarks at elevations $>2000 \mathrm{~m}$ (mountainous area) and 104 benchmarks at elevations $<2000 \mathrm{~m}$ (moderate area). Table 8 presents the statistics of the differences between the gravimetric geoid models and the GPS leveling

Table 6 Statistics of the differences between the gravimetric geoid models based on different geoidquasigeoid separations and the GPS leveling measured geoid heights (unit: $\mathbf{m}$ )

\begin{tabular}{lllll}
\hline $\begin{array}{l}\text { Gravimetric geoid } \\
\text { model }\end{array}$ & Min & Max & Mean & SD \\
\hline With $\Delta_{H M}$ & 0.712 & 1.094 & 0.872 & 0.058 \\
With $\Delta_{F R}$ & 0.710 & 1.048 & 0.863 & 0.053 \\
\hline
\end{tabular}

measured geoid heights at elevations $>2000 \mathrm{~m}$ and elevations $<2000 \mathrm{~m}$, respectively. With the increasing of the spacing between terrestrial gravity points, the number of resampled terrestrial data points decreases rapidly. For the geoid models in group B, the standard deviations of the differences rise quickly with the terrestrial gravity point spacing above $10 \mathrm{~km}$ in the mountainous area and $20 \mathrm{~km}$ in the moderate area, which is not the case if terrestrial gravity point spacings are less than or equal to $10 \mathrm{~km}$ in the mountainous area and $20 \mathrm{~km}$ in the moderate area, respectively.

Comparing the performance of gravimetric geoid models in group A and group B (Table 8), the accuracy improvements contributed by airborne gravity data are relevant to the spacing of the used terrestrial gravity data. In the cases of terrestrial data with original spacing and the spacing of $5 \mathrm{~km}, 10 \mathrm{~km}$ and $15 \mathrm{~km}$, the inclusions of airborne gravity data improved the accuracies of the geoid models by $6.3 \%-11.9 \%$ in the mountainous area and $9.4 \%-12.3 \%$ in the moderate area. In the cases of terrestrial data with the spacing of $20 \mathrm{~km}$, $25 \mathrm{~km}, 30 \mathrm{~km}, 35 \mathrm{~km}$ and $40 \mathrm{~km}$, the additions of airborne data improved the geoid models in the accuracy by $13.4 \%-19.8 \%$ in the mountainous area and $12.7 \%-21 \%$ in the moderate area. The results demonstrate that: (1) airborne gravity data can only slightly improve the accuracy of geoid model if the used terrestrial gravity data are densely distributed with the spacing less than or equal to $15 \mathrm{~km}$; (2) airborne gravity data are capable of effectively filling the data gaps of terrestrial gravity and obviously improving the geoid model accuracy when combined with sparsely distributed terrestrial data with the spacing larger than $15 \mathrm{~km}$.

Overall, the improvement rates in the geoid model accuracies contributed by airborne data in the mountainous area are not superior to those in the moderate area. On the contrary, slight better improvement rates in the geoid model accuracies are observed in the moderate area than in the mountainous area. This contradicts to our expectation that airborne gravity data will lead to greater accuracy improvement for the geoid models in the mountainous area than those in the moderate area. The possible reason may be that, in the Colorado experiment area, the spatial distribution of terrestrial gravity data in the mountainous area is as dense as that in the moderate area, and even denser in some particular areas (Fig. 3), which is not the usual case for mountainous areas.

For each selection of terrestrial gravity point spacing in Table 8, the combinations of GOCO06S model, terrestrial and airborne gravity data lead to the gravimetric geoid models (group A) with the accuracy ranging from $4.7 \mathrm{~cm}$ to $5.2 \mathrm{~cm}$ in terms of the standard deviation in the moderate area. In the mountainous areas, the gravimetric 

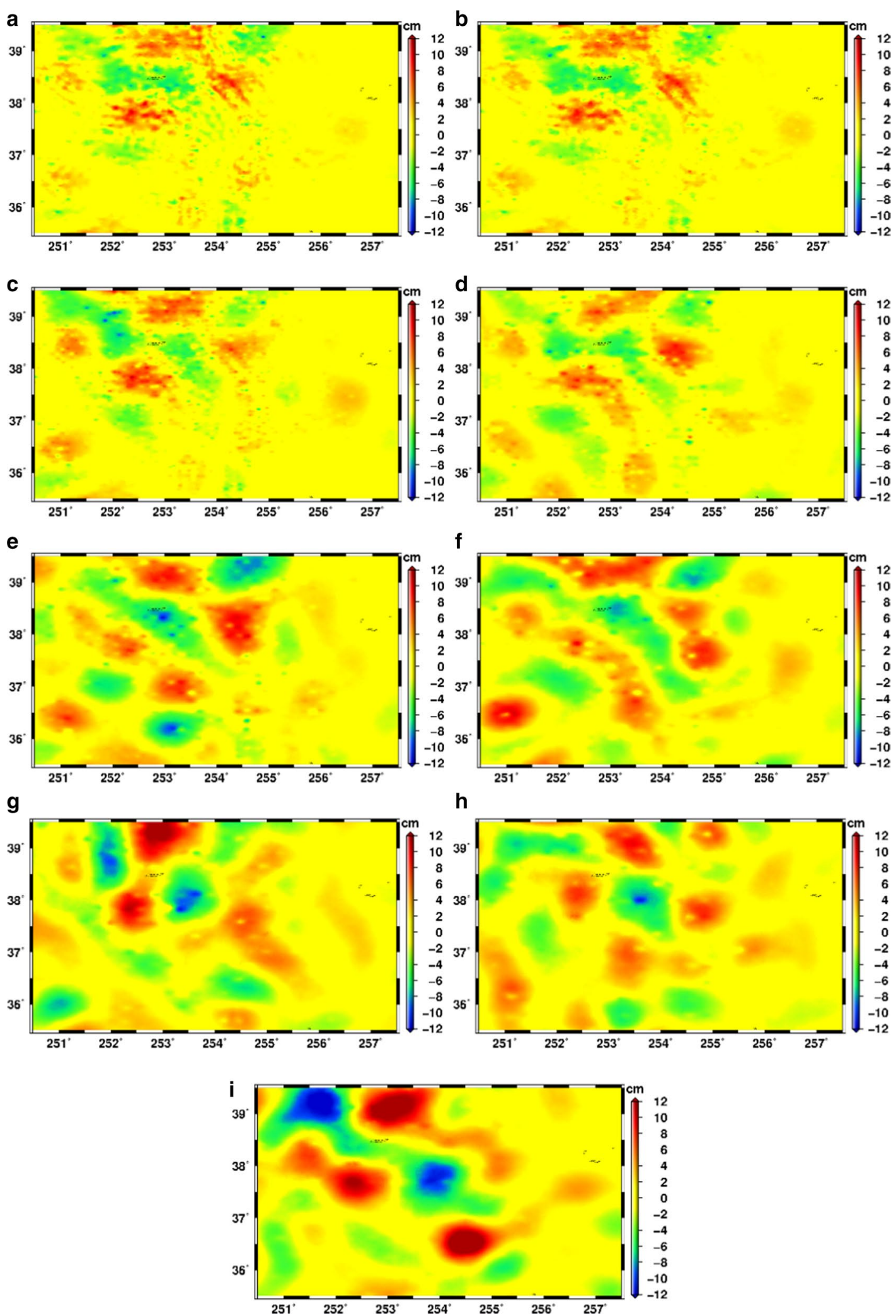

Fig. 9 Changes of geoid heights contributed from airborne gravity data when combined with terrestrial gravity data of different spatial distribution and density. Terrestrial gravity data point spacings are: a original spacing. b $5 \mathrm{~km}$. c $10 \mathrm{~km}$. d $15 \mathrm{~km}$. e $20 \mathrm{~km}$. f $25 \mathrm{~km}$. g $30 \mathrm{~km}$. h $35 \mathrm{~km}$. i $40 \mathrm{~km}$ 
Table 7 Statistics of the changes of geoid heights contributed from airborne gravity data (unit: $\mathrm{m}$ )

\begin{tabular}{lllll}
\hline $\begin{array}{l}\text { Terrestrial gravity } \\
\text { point spacing }\end{array}$ & Min & Max & Mean & SD \\
\hline Original spacing & -0.113 & 0.105 & 0.001 & 0.019 \\
$5 \mathrm{~km}$ & -0.111 & 0.097 & 0.001 & 0.020 \\
$10 \mathrm{~km}$ & -0.100 & 0.116 & 0.001 & 0.021 \\
$15 \mathrm{~km}$ & -0.099 & 0.090 & 0.002 & 0.021 \\
$20 \mathrm{~km}$ & -0.114 & 0.106 & 0.002 & 0.029 \\
$25 \mathrm{~km}$ & -0.082 & 0.104 & 0.002 & 0.029 \\
$30 \mathrm{~km}$ & -0.109 & 0.139 & 0.002 & 0.032 \\
$35 \mathrm{~km}$ & -0.111 & 0.099 & 0.002 & 0.028 \\
$40 \mathrm{~km}$ & -0.137 & 0.171 & 0.002 & 0.041 \\
\hline
\end{tabular}

geoid models of group A agree with the GPS leveling measured geoid heights in the standard deviation of the differences better than $7.2 \mathrm{~cm}$, except for the case of terrestrial gravity data spaced at $35 \mathrm{~km}$. This level of geoid model accuracy demonstrates the good quality of the GRAV-D airborne gravity observations in this area and the correctness and reliability of the spectral combination based geoid modeling method and procedure.

\section{Conclusions}

We have described the computations of $1^{\prime} \times 1^{\prime}$ gravimetric geoid models as our contribution to the IAG Colorado geoid experiment. A series of gravimetric geoid models in the varied topography area of Colorado were derived based on the different data combination modes of satellite gravity model, terrestrial and GRAV-D airborne gravity data using the spectral combination method, and then validated against the historic GPS leveling measured geoid heights at 194 benchmarks provided by the NGS. The gravimetric geoid model, based on the combination of GOCO06S model and terrestrial gravity data, agrees with the GPS leveling measured geoid heights in $5.8 \mathrm{~cm}$ in terms of the standard deviation of the discrepancies, and this agreement reduces to $5.3 \mathrm{~cm}$ after the inclusion of airborne gravity data into the combination.

Based on the comparisons and analyses using the GPS leveling data, the accuracies of geoid solutions based on four satellite gravity models and three high-degree reference gravity models truncated to the same degree agree with each other in millimeter level. Additionally, the rigorous modeling of geoid-quasigeoid separation (Flury and Rummel 2009) improved the geoid model accuracy by $8.6 \%$ on the basis of the traditional approximation formula (Heiskanen and Moritz 1967), confirming the necessity of using the rigorous formula

Table 8 Statistics of the differences between the gravimetric geoid models based on different data combination modes and the GPS leveling measured geoid heights (unit: $\mathbf{m}$ )

\begin{tabular}{|c|c|c|c|c|c|c|c|}
\hline \multirow{2}{*}{\multicolumn{2}{|c|}{$\begin{array}{l}\text { Terrestrial gravity } \\
\text { point spacing } \\
\text { and number }\end{array}$}} & \multirow[t]{2}{*}{$\begin{array}{l}\text { Elevation of GPS } \\
\text { leveling benchmark }(\mathrm{m})\end{array}$} & \multicolumn{2}{|c|}{ Group B:GOCO06S + Terrestrial } & \multicolumn{2}{|c|}{$\begin{array}{l}\text { Group } \\
\text { A:GOCO06S + Terrestrial + airborne }\end{array}$} & \multirow[t]{2}{*}{$\begin{array}{l}\text { Accuracy } \\
\text { improvement }\end{array}$} \\
\hline & & & Mean & SD & Mean & SD & \\
\hline \multirow[t]{2}{*}{ OS } & 59,303 & $>2000$ & 0.868 & 0.064 & 0.865 & 0.060 & $6.3 \%$ \\
\hline & & $<2000$ & 0.855 & 0.052 & 0.856 & 0.047 & $9.6 \%$ \\
\hline \multirow[t]{2}{*}{$5 \mathrm{~km}$} & 13,063 & $>2000$ & 0.869 & 0.067 & 0.870 & 0.059 & $11.9 \%$ \\
\hline & & $<2000$ & 0.861 & 0.053 & 0.857 & 0.047 & $11.3 \%$ \\
\hline \multirow[t]{2}{*}{$10 \mathrm{~km}$} & 4600 & $>2000$ & 0.860 & 0.067 & 0.862 & 0.061 & $9 \%$ \\
\hline & & $<2000$ & 0.857 & 0.054 & 0.854 & 0.047 & $12.3 \%$ \\
\hline \multirow[t]{2}{*}{$15 \mathrm{~km}$} & 2212 & $>2000$ & 0.864 & 0.078 & 0.863 & 0.072 & $7.7 \%$ \\
\hline & & $<2000$ & 0.857 & 0.053 & 0.852 & 0.048 & $9.4 \%$ \\
\hline \multirow[t]{2}{*}{$20 \mathrm{~km}$} & 1248 & $>2000$ & 0.857 & 0.082 & 0.860 & 0.070 & $14.6 \%$ \\
\hline & & $<2000$ & 0.853 & 0.055 & 0.851 & 0.048 & $12.7 \%$ \\
\hline \multirow[t]{2}{*}{$25 \mathrm{~km}$} & 824 & $>2000$ & 0.872 & 0.082 & 0.864 & 0.071 & $13.4 \%$ \\
\hline & & $<2000$ & 0.852 & 0.062 & 0.847 & 0.049 & $21 \%$ \\
\hline \multirow[t]{2}{*}{$30 \mathrm{~km}$} & 569 & $>2000$ & 0.840 & 0.086 & 0.853 & 0.069 & $19.8 \%$ \\
\hline & & $<2000$ & 0.848 & 0.065 & 0.845 & 0.052 & $20 \%$ \\
\hline \multirow[t]{2}{*}{$35 \mathrm{~km}$} & 416 & $>2000$ & 0.857 & 0.101 & 0.856 & 0.085 & $15.8 \%$ \\
\hline & & $<2000$ & 0.843 & 0.062 & 0.844 & 0.050 & $19.4 \%$ \\
\hline \multirow[t]{2}{*}{$40 \mathrm{~km}$} & 322 & $>2000$ & 0.859 & 0.086 & 0.860 & 0.069 & $19.8 \%$ \\
\hline & & $<2000$ & 0.856 & 0.064 & 0.853 & 0.051 & $20.3 \%$ \\
\hline
\end{tabular}

OS stands for original spacing 
for quasigeoid to geoid transformation in this high and rugged area.

The contributions of airborne gravity data to geoid modeling were quantified based on the original and resampled terrestrial gravity datasets with the spacing of $5 \mathrm{~km}, 10 \mathrm{~km}, 15 \mathrm{~km}, 20 \mathrm{~km}, 25 \mathrm{~km}, 30 \mathrm{~km}, 35 \mathrm{~km}$ and $40 \mathrm{~km}$, respectively. In the cases of terrestrial data spacings are less than or equal to $15 \mathrm{~km}$, the geoid model accuracies were slightly improved by $6.3 \%-11.9 \%$ in the mountainous area (elevations $>2000 \mathrm{~m}$ ) and 9.4\%$12.3 \%$ in the moderate area (elevations $<2000 \mathrm{~m}$ ) after the inclusions of airborne data. In the cases of terrestrial data spacings are larger than $15 \mathrm{~km}$, and the additions of airborne data collected at the high altitude of $\sim 6.2 \mathrm{~km}$ improved the geoid models in the accuracy by $13.4 \%-19.8 \%$ in the mountainous area and $12.7 \%-$ $21 \%$ in the moderate area, demonstrating the capability of airborne gravity data for effectively filling terrestrial gravity data gaps and obviously improving the accuracy of geoid models derived from the data combination.

\begin{abstract}
Abbreviations
JWG: Joint Working Group; IHRS: International Height Reference System; IAG: International Association of Geodesy; NGS: National Geodetic Survey;i USA: United States of America; GPS: Global positioning system; DEM: Digital elevation model; LSC: Least squares collocation; RTM: Residual terrain model; KTH: Royal Institute of Technology, Sweden; GRS80: Geodetic reference system 1980; GSVS: Geoid slope validation survey; GRAV-D: Gravity for the Redefinition of the American Vertical Datum; SRTM: Shuttle radar topography mission; TAGS: Turn-key airborne gravimetry system; ITRF2008: International Terrestrial Reference Frame 2008; RMS: Root mean square; OPUS: Online positioning user service; SD: Standard derivation; ICGEM: International Centre for Global Earth Models; TIM6: GO_CONS_GCF_2_TIM_R6; DIR6: GO_CONS_GCF_2_DIR_R6; SLR: Satellite laser ranging.
\end{abstract}

\section{Acknowledgements}

The authors thank the US National Geodetic Survey for sharing the terrestrial, airborne gravity and GPS leveling data. We thank Dr. Yan Ming Wang from the US National Geodetic Survey and Dr. Laura Sánchez from the Technical University of Munich for their efforts in the coordination of Colorado geoid experiment. We thank Dr. Yan Ming Wang, Dr. Jianliang Huang from Natural Resources Canada and Dr. Jonas Ågren from Lantmäteriet of Sweden for constructive discussions. We also thank the two anonymous reviewers for their constructive suggestions and comments. Some figures in this article are drawn using the software of Generic Mapping Tools.

\section{Authors' contributions}

TJ designed the study, performed the methodology research, data processing and analysis and drafted the manuscript. YD performed the GPS leveling data validation and analysis, and drafted part of the manuscript. CZ conducted the computation of RTM effects and the analysis of geoid-quasigeoid separations. All authors read and approved the final manuscript.

\section{Funding}

This study was supported by the National Natural Science Foundation of China (No. 41674024, 42074020).

\section{Availability of data and materials}

The geoid models and intermediate data are available from the author upon reasonable request. Correspondence and requests for data should be addressed to TJ.

\section{Competing interests}

The authors declare that they have no competing interests.

Received: 15 July 2020 Accepted: 30 September 2020

Published online: 11 December 2020

\section{References}

Ågren J (2004) Regional geoid determination methods for the era of satellite gravimetry. PhD dissertation, Royal Institute of Technology

Barthelmes F, Köhler W (2016) International Centre for Global Earth Models (ICGEM), In: Drewes H, Kuglitsch F, Adám J et al., eds The Geodesists Handbook 2016. J Geodesy 90 (10): 907-1205. doi: https://doi. org/10.1007/s00190-016-0948-z

Bayoud FA, Sideris MG (2003) Two different methodologies for geoid determination from surface and airborne gravity data. Geophys J Int 155:914-922

Brockmann JM, Schubert T, Mayer-Gürr T, Schuh WD (2019) The Earth's gravity field as seen by the GOCE satellite - an improved sixth release derived with the time-wise approach. GFZ Data Services. https://doi.org/10.5880/ ICGEM.2019.003

Dimitrijevich I (1987) WGS84 ellipsoidal gravity formula and gravity anomaly conversion equations. Defense Mapping Agency Acrospace Center, Springfield

Drinkwater MR, Floberghagen R, Haagmans R, Muzi D, Popescu A. (2003) GOCE: ESA's First Earth Explorer Core Mission. In: Beutler G, Drinkwater MR, Rummel R, Von Steiger R (eds) Earth Gravity Field from Space—from sensors to earth sciences. Space Sciences Series of ISSI, vol 17. Springer, Dordrecht. doi: https://doi.org/10.1007/978-94-017-1333-7_3

Farr TG, Rosen P, Caro E, Crippen R, Duren R, Hensley S, Kobrick M, Paller M, Rodriguez E, Roth L, Seal D, Shaffer S, Shimada J, Umland J, Werner M, Oskin M, Burbank D, Alsdorf D (2007) The shuttle radar topography mission. Rev Geophys 45(2):RG2004. https://doi.org/10.1029/2005RG000183

Flury J, Rummel R (2009) On the geoid-quasigeoid separation in mountain areas. J Geod 83:829-847. https://doi.org/10.1007/s00190-009-0302-9

Forsberg R (1984) A study of terrain reductions, density anomalies and geophysical inversion methods in gravity field modelling. Reports of the Department of Geodetic Science and Surveying, \#355. The Ohio State University, Columbus

Forsberg R, Olesen A, Bastos L, Gidskehaug A, Meyer U, Timmen L (2000) Airborne geoid determination. Earth Planets Space 52:863-866

Forsberg R, Olesen A (2010) Airborne gravity field determination. In: Xu G (ed) Sciences of Geodesy - I. Springer-Verlag, Berlin Heidelberg, pp 83-104

Forsberg R, Sahrum S, Alshamsi A, Din AHM (2012) Coastal geoid improvement using airborne gravimetric data in the United Arab Emirates. Int J Phys Sci 7(45):6012-6023

Förste C, Bruinsma S, Abrikosov O, Lemoine JM, Marty JC, Flechtner F, Balmino G, Barthelmes F, Biancale R (2014) EIGEN-6C4 The latest combined global gravity field model including GOCE data up to degree and order 2190 of GFZ Potsdam and GRGS Toulouse. GFZ Data Services. https://doi. org/10.5880/icgem.2015.1

Förste C, Abrykosov O, Bruinsma S, Dahle C, König R, Lemoine JM (2019) ESA's Release 6 GOCE gravity field model by means of the direct approach based on improved filtering of the reprocessed gradients of the entire mission (GO_CONS_GCF_2_DIR_R6). GFZ Data Services. https://doi. org/10.5880/ICGEM.2019.004

GRAV-D Science Team (2017a) GRAV-D general airborne gravity data user manual. Theresa Damiani, Monica Youngman, and Jeffery Johnson, ed. Version 2.1. https://www.ngs.noaa.gov/GRAV-D/data_products.shtml

GRAV-D Science Team (2017b) Gravity for the Redefinition of the American Vertical Datum (GRAV-D) Project, Airborne Gravity Data; Block MS05. https ://www.ngs.noaa.gov/GRAV-D/data_PS02.shtml

GRAV-D Science Team (2017c) Block MS05 (Mountain South 05); GRAV-D Airborne Gravity Data User Manual. Monica A. Youngman and Jeffery A. Johnson, ed. Version BETA. Available online at: https://www.ngs.noaa. gov/GRAV-D/data_MS05.shtml

Heiskanen WA, Moritz H (1967) Physical geodesy. Freeman, San Francisco

Hofmann-Wellenhof B, Moritz H (2005) Physical geodesy. Springer, Wien New York

Hwang C, Hsiao YS, Shih HC, Yang M, Chen KH, Forsberg R, Olesen AV (2007) Geodetic and geophysical results from a Taiwan airborne gravity survey: 
data reduction and accuracy assessment. J Geophys Res Solid Earth 112:B04407. https://doi.org/10.1029/2005JB004220

Ince ES, Barthelmes F, Reißland S, Elger K, Förste C, Flechtner F, Schuh H (2019) ICGEM-15 years of successful collection and distribution of global gravitational models, associated services and future plans. Earth Syst Sci Data 11:647-674. https://doi.org/10.5194/essd-11-647-2019

Jekeli C, Yang HJ, Kwon JH (2013) Geoid determination in South Korea from a combination of terrestrial and airborne gravity anomaly data. J Korean Soc Surveying Geodesy Photogrammetry Cartography 31(6-2):567-576

Jiang T, Wang YM (2016) On the spectral combination of satellite gravity model, terrestrial and airborne gravity data for local gravimetric geoid computation. J Geod 90:1405-1418

Klees R, Tenzer R, Prutkin I, Wittwer T (2008) A data-driven approach to local gravity field modelling using spherical radial basis functions. J Geod 82(8):457-471

Kvas A, Mayer-Gürr T, Krauss S, Brockmann JM, Schubert T, Schuh WD, Pail R, Gruber T, Jäggi A, Meyer U (2019) The satellite-only gravity field model GOCO06s. GFZ Data Services. https://doi.org/10.5880/ICGEM.2019.002

Mayer-Gürr T, Behzadpur S, Ellmer M, Kvas A, Klinger B, Strasser S, Zehentner N (2018) ITSG-Grace2018 - monthly. GFZ data services, Daily and Static Gravity Field Solutions from GRACE. https://doi.org/10.5880/ICGEM .2018 .003

Moritz H (2000) Geodetic reference system 1980. J Geod 74:128-133

Nagy D, Papp G, Benedek J (2000) The gravitational potential and its derivatives for the prism. J Geod 74:552-560. https://doi.org/10.1007/s0019 $0-006-0094-0$

Novák P, Heck B (2002) Downward continuation and geoid determination based on band-limited airborne gravity data. J Geod 76:269-278

Panet I, Kuroishi Y, Holschneider M (2010) Wavelet modelling of the gravity field by domain decomposition methods: an example over Japan. Geophys J Int 184(1):203-219

Pavlis NK, Holmes SA, Kenyon S, Factor JK (2012) The development and evaluation of the Earth Gravitational Model 2008 (EGM2008). J Geophys Res 117:B04406

Pavlis NK, Holmes SA, Kenyon SC, Factor JK (2013) Correction to "The Development and Evaluation of the Earth Gravitational Model 2008 (EGM2008)". J Geophys Res 118(5):2633

Santos MC, Vaníček P, Featherstone WE, Kingdon R, Ellmann A, Martin BA, Kuhn $M$, Tenzer R (2006) The relation between rigorous and Helmert's definitions of orthometric heights. J Geod 80:691. https://doi.org/10.1007/ s00190-006-0086-0

Scheinert M, Müller J, Dietrich R, Damaske D, Damm V (2008) Regional geoid determination in Antarctica utilizing airborne gravity and topography data. J Geod 82:403-414

Schmidt M, Fengler M, Mayer-Gürr T, Eicker A, Kusche J, Sánchez L, Han S-H (2007) Regional gravity modeling in terms of spherical base functions. J Geod 81(1):17-38

Shih HC, Hwang C, Barriot JP, Mouyen M, Corréia P, Lequeux D, Sichoix L (2015) High-resolution gravity and geoid models in Tahiti obtained from new airborne and land gravity observations: data fusion by spectral combination. Earth, Planet Space 67:124. https://doi.org/10.1186/s4062 3-015-0297-9
Sjöberg LE (1981) Least-squares combination of satellite and terrestrial data in physical geodesy. Ann Geophys 37:25-30

Sjöberg LE (1986) Comparison of Some Methods of Modifying Stokes' formula. Boll Geod Sci Affini 45(3):229-248

Smith DA, Holmes SA, Li XP, Guillaume S, Wang YM, Bürki B, Roman DR, Damiani TM (2013) Confirming regional $1 \mathrm{~cm}$ differential geoid accuracy from airborne gravimetry: the Geoid Slope Validation Survey of 2011. J Geod 87:885-907

Tapley BD, Bettadpur S, Watkins M, Reigber C (2004) The gravity recovery and climate experiment: mission overview and early results. Geophys Res Lett 31(9):L09607. https://doi.org/10.1029/2004GL019920

Tscherning CC, Knudsen P, Forsberg R (1991) Description of the GRAVSOFT package. Technical Report, Geophysical Institute, University of Copenhagen

Wang YM, Saleh J, Roman DR (2012) The US Gravimetric Geoid of 2009 (USGG2009): model development and evaluation. J Geod 86:165-180

Wang YM, Becker C, Mader G, Martin D, Li XP, Jiang T, Breidenbach S, Geoghegan C, Winester D, Guillaume S, Bürki B (2017) The Geoid Slope Validation Survey 2014 and GRAV-D airborne gravity enhanced geoid comparison results in lowa. J Geod 91(10):1261-1276. https://doi.org/10.1007/s0019 0-017-1022-1

Wang YM, Sánchez L, Ågren J, Huang JL, Forsberg R, Abd-Elmotaal HA, Barzaghi R, Bašić T, Carrion D, Claessens S, Erol B, Erol S, Filmer M, Grigoriadis VN, Isik MS, Jiang T, Koç Ö, Li XP, Ahlgren K, Krcmaric J, Liu Q, Matsuo K, Natsiopoulos DA, Novák P, Pail R, Pitonák M, Schmidt M, Varga M, Vergos GS, Véronneau M, Willberg M, Zingerle P (2020) Colorado geoid computation experiment-Overview and Summary. Submitted to Journal of Geodesy

Wenzel HG (1982) Geoid computation by least-squares spectral combination using intergral kernels. In: Proceedings of the General IAG Meeting, Tokyo, pp 438-453

Wittwer T (2009) Regional gravity field modeling with radial basis functions. PhD dissertation, NCG, Nederlandse Commissie voor Geodesie, Netherlands Geodetic Commission, Delft, the Netherlands

Zilkoski DB (1992) North American Vertical Datum and International Great Lakes Datum: They Are Now One and the Same. Proceedings of the U.S. Hydrographic Conference '92, Baltimore, Maryland

Zingerle P, Pail R, Gruber T, Oikonomidou X (2019) The experimental gravity field model XGM2019e. GFZ Data Services. https://doi.org/10.5880/ ICGEM.2019.007

\section{Publisher's Note}

Springer Nature remains neutral with regard to jurisdictional claims in published maps and institutional affiliations.

\section{Submit your manuscript to a SpringerOpen ${ }^{\odot}$ journal and benefit from:}

- Convenient online submission

- Rigorous peer review

- Open access: articles freely available online

- High visibility within the field

- Retaining the copyright to your article

Submit your next manuscript at $\boldsymbol{\nabla}$ springeropen.com 